\title{
Retraction Note: CD109 Mediates Cell Survival in Hepatocellular Carcinoma Cells
}

\author{
Guijuan Zong ${ }^{1} \cdot$ Zhiwei Xu $^{2,3}$. Shusen Zhang ${ }^{4} \cdot$ Yifen Shen $^{2} \cdot$ Huiyuan $\mathrm{Qiu}^{2} \cdot$ Guizhou Zhu ${ }^{2} \cdot$ Song He ${ }^{1} \cdot \mathrm{Tao} \mathrm{Tao}^{2}$. \\ Xudong Chen ${ }^{1}$
}

Published online: 11 November 2019

(c) Springer Science+Business Media, LLC, part of Springer Nature 2019

\section{Retraction to: \\ Dig Dis Sci (2016) 61:2303-2314 https://doi.org/10.1007/s10620-016-4149-7}

This article [1] is retracted at the request of Editor-in-Chief.

The GAPDH band in Figure 1A and Figure 5A in [1] appears to be duplicated from Figure 4A in [2].

The PCNA and p27 bands in Figure 4D in [1] appear to be duplicated from portions of Figure 4A in [3] and Figure $1 \mathrm{~A}$ in [2].

The bands in Figure 1A, 4D and 4D [1] appear to be identical.

Figure 7B in [1] appears to be duplicated from [4].

This article contains substantial text overlap with [5-10].

All authors agree to this retraction.

The original article can be found online at https://doi.org/10.1007/ s10620-016-4149-7.

Tao Tao

taotao201504@163.com

Xudong Chen

nantong201504@163.com

1 Department of Pathology, Affiliated Cancer Hospital of Nantong University, Nantong 226001, Jiangsu Province, People's Republic of China

2 Jiangsu Province Key Laboratory for Inflammation and Molecular Drug Target, Department of Immunology, Medical College, Nantong University, Nantong 226001, Jiangsu Province, People's Republic of China

3 Division of Regulatory Glycobiology, Institute of Molecular Biomembrane and Glycobiology, Tohoku Pharmaceutical University, Sendai, Miyagi 981-8558, Japan

4 Department of Gastroenterology, Affiliated Hospital of Nantong University, Nantong 226001, Jiangsu Province, People's Republic of China

\section{References}

1. Zong G, Xu Z, Zhang S, et al. CD109 mediates cell survival in hepatocellular carcinoma cells. Dig Dis Sci. 2016;61:2303-2314. https://doi.org/10.1007/s10620-016-4149-7.

2. Wu X, Zhang H, Chen D, et al. Up-regulation of CCT8 related to neuronal apoptosis after traumatic brain injury in adult rats. Neurochem Res. 2015;40:1882-1891. https://doi.org/10.1007/s1106 4-015-1683-1.

3. Zhang H, Liu Y, Li Y, et al. The expression of CAP1 after traumatic brain injury and its role in astrocyte proliferation. $J \mathrm{Mol}$ Neurosci. 2014;54:653-663. https://doi.org/10.1007/s1203 1-014-0363-y.

4. Xu Z, Li X, Chen J, et al. USP11, deubiquitinating enzyme, associated with neuronal apoptosis following intracerebral hemorrhage. J Mol Neurosci. 2016;58:16-27. https://doi.org/10.1007/ s12031-015-0644-0.

5. Chen H-W, Huang X-D, Li H-C, et al. Expression of FOXJI in hepatocellular carcinoma: correlation with patient's prognosis and tumor cell proliferation. Mol Carcinog. 2012;52:641-659. https:// doi.org/10.1002/mc.21904.

6. Lu C, Liu G, Cui X, et al. Expression of SGTA correlates with prognosis and tumor cell proliferation in human hepatocellular carcinoma pathology and oncology research. Pathol Oncol Res. 2013. https://doi.org/10.1007/s12253-013-9657-6.

7. Huang X, Wang X, Cheng C, et al. Chaperonin containing TCP1, subunit 8 (CCT8) is upregulated in hepatocellular carcinoma and promotes HCC proliferation. APMIS. 2014;12:1070-1079. https ://doi.org/10.1111/apm.12258.

8. Zhu G, Shi W, Fan H, et al. HES5 promotes cell proliferation and invasion through activation of STAT3 and predicts poor survival. Exp Mol Pathol. 2015;99:474-484.

9. Zhu T, Ji Z, Xu C, et al. Expression and prognostic role of SKIP in human breast carcinoma. J Mol Histol. 2014;2014:169-180. https://doi.org/10.1007/s11357-013-9586-z.

10. Zhang T, Zhang X, Shi W, et al. The DNA damage repair protein $\mathrm{Ku} 70$ regulates tumor cell and hepatic carcinogenesis by interacting with FOXO4. Pathol Res Pract. 2016;212:153. https ://www.sciencedirect.com/science/article/pii/S03440338153006 49?via\%3Dihub.

Publisher's Note Springer Nature remains neutral with regard to jurisdictional claims in published maps and institutional affiliations. 